\title{
Dental and Medical Students' Knowledge and Attitude toward COVID-19: A Cross-Sectional Study from Pakistan
}

\author{
Saqib Ali ${ }^{1}$ Beenish Fatima Alam² Faraz Farooqi $^{3} \quad$ Khalid Almas $^{4} \quad$ Sara Noreen $^{5}$
}

${ }^{1}$ Department of Biomedical Dental Sciences, College of Dentistry, Imam Abdulrahman Bin Faisal University, Dammam, Saudi Arabia

2Department of Oral Biology, Bahria University Medical and Dental College, Karachi, Pakistan

${ }^{3}$ Department of Academic Affairs, College of Dentistry, Imam Abdulrahman Bin Faisal University, Dammam, Saudi Arabia

${ }^{4}$ Department of Preventive Dental Sciences, College of Dentistry, Imam Abdulrahman Bin Faisal University, Dammam, Saudi Arabia

${ }^{5}$ Department of Medicine, Khyber Teaching Hospital, Peshawar, Pakistan

Eur J Dent:2020;14(suppl S1):S97-S104

\begin{abstract}
Address for correspondence Saqib Ali, BDS, MFGDP, MSc, Department of Biomedical Dental Sciences, College of Dentistry, Imam Abdulrahman Bin Faisal University, Dammam 31441, Kingdom of Saudi Arabia (e-mail: drsaqiibali@gmail.com).
\end{abstract}

\begin{abstract}
Objective The aims of this study were to investigate the awareness, knowledge, and attitudes of Pakistani medical and dental undergraduate students toward COVID-19 during the surge of its outbreak.

Materials and Methods The multicentered, cross-sectional study was carried out nationwide among undergraduate medical and dental students. A convenience sampling technique was used. A self-developed online questionnaire was pretested to be completed by the participants. It was distributed using social media. The survey was comprised of questions related to demographics, health status, general hygiene perception, understanding, and the learning attitudes of the students. Comparisons of the knowledge scores and the attitude responses with the demographic information were done using the independent $t$-test, one-way ANOVA, and Chi-square, as appropriate.

Results Of the 937 total respondents, 353 (38\%) were males and 582 (62\%) were females; two students did not mark their gender. Of these, 680 (73\%) were dental students and 257 (27\%) were medical students. The mean knowledge score of the female dental students $(5.15 \pm 1.08)$ was significantly higher than that of the male students $(4.87 \pm 1.09)$. Overall, the mean knowledge score was statistically higher among the medical students in comparison to the dental students $(5.21 \pm 1.15$, Keywords $5.05 \pm 1.09 ; p=0.054)$, respectively.

- attitude

- awareness

- COVID-19

- knowledge

- Pakistan

Conclusion The medical and dental students were both aware of the importance of the use of a mask. The medical students had a greater awareness regarding the mode of transmission, symptoms, and origin of COVID-19. However, the dental students showed better understanding of the use of surgical masks and the correct protocol for hand washing. Social media was considered the main source for COVID-19 related information.
\end{abstract}

DOI https://doi.org/ $10.1055 / \mathrm{s}-0040-1719219$ ISSN 1305-7456.

\footnotetext{
(C) 2020. European Journal of Dentistry.

This is an open access article published by Thieme under the terms of the Creative Commons Attribution-NonDerivative-NonCommercial-License, permitting copying and reproduction so long as the original work is given appropriate credit. Contents may not be used for commercial purposes, or adapted, remixed, transformed or built upon. (https://creativecommons.org/licenses/by-nc-nd/4.0/)

Thieme Medical and Scientific Publishers Pvt. Ltd., A-12, 2nd Floor, Sector 2, Noida-201301 UP, India
} 


\section{Introduction}

The coronavirus disease 2019 (COVID-19), a recently identified viral infection, is a contagious disease that is known for causing acute respiratory syndrome. ${ }^{1}$ Severe acute respiratory syndrome coronavirus-2 (SARS-COV-2) is a ribonucleic acid (RNA) virus that has crown-like spikes identified on its cell envelope. The coronavirus can be subdivided into four subtypes: $\alpha, \beta, \delta$, and $\gamma .{ }^{2}$ Coronaviruses have an exceptional semblance within their structure and genomic expression. $^{3}$ Initially, it was thought that these viruses only infected certain animals and birds; however, with the spread of SARS-COV-2, it is known to be transmitted from one human to another. ${ }^{4}$ It can cause symptoms such as fever, sore throat, dyspnea, cough, pneumonia, and rhinorrhea. It can also involve the gastrointestinal tract, causing vomiting and diarrhea. The main route of transmission is through respiratory droplets that can broadcast through coughing or sneezing. ${ }^{5,6}$ Although the World Health Organization (WHO) has delineated an incubation period for the virus as ranging from 2 to 10 days; recently conducted studies have anticipated an incubation period lasting longer than 2 weeks. ${ }^{7.8}$

The WHO identified the coronavirus as a general public health emergency on January 30, 2020. ${ }^{9}$ Then, in early March, many countries from across the globe reported a tremendous increase in the number of new cases. Since March 12, 2020, among 118 different countries, approximately 142,539 cases and 5,393 deaths have been confirmed as of this writing. ${ }^{10}$ The first coronavirus patient in Pakistan was reported on February 26, 2020. ${ }^{11}$ Since June 17, 2020, there have been 154,760 confirmed cases; the rate of death reported is 2,975 and the number of patients recovered from this condition in the country is $58,437 .^{12}$

Since the declaration of COVID-19, the government of Pakistan has been trying to reinforce safety awareness, and it has implemented lockdown measures to reduce the spread of this infection. Likewise, the WHO has recommended self-isolation, social distancing, and lockdown as important measures against the spread of this disease. ${ }^{13}$

To prevent the further spread, research conducted by Qian et al identified three basic strategies that should be followed: (1) monitoring the causative factors responsible for spreading the disease, (2) preventing the further transmission, and (3) providing protection to vulnerable populations. ${ }^{14}$ Along with initiating a general public awareness drive, Pakistan's National Institute of Health has played an essential role in formulating and disseminating protocols against the prevention and transmission of COVID-19. This has encompassed providing information regarding the use of personal protective equipment and face masks as well as following an adequate hand and general body hygiene regime. ${ }^{15}$ As of this writing, no antiviral medication or vaccine is available for providing protection against COVID-19. However, symptomatic treatment options are available that should be followed in case of susceptibility. ${ }^{16}$

Healthcare workers are at great risk during this COVID-19 outbreak. ${ }^{17} \mathrm{~A}$ study by Ikhlaq et al on the medical undergraduate students enrolled in Lahore Medical College identified adequate knowledge and awareness regarding COVID-19. ${ }^{18}$ Likewise, research conducted by Ahmed et al, among the undergraduate dental and medical students of three institutes of Karachi, revealed that the students had adequate information regarding COVID-19; however, they were quite concerned regarding the safety and diagnostic measures required for coronavirus. ${ }^{19}$ This current study is directed toward determining the level of knowledge, attitude, and perception among the dental and medical undergraduate students across Pakistan.

\section{Materials and Methods}

The multicentered, cross-sectional investigation was performed among undergraduate students studying in various medical and dental colleges across Pakistan. Verbal consent to fill out the questionnaires was obtained from the students. The questionnaires were anonymous, for the privacy and confidentiality of all of the information stated in the research. Ethical approval of the study was obtained from the Ethical Review Committee of the Bahria University Medical and Dental College, Karachi, Pakistan (ERC 55/2020). The study was in accord with the Helsinki Convention.

Due to strict lockdown, an online survey form was formulated on Google Forms (Alphabet; Mountain View, California, United States). It was distributed through social media to students across the country. Data were collected from March to May 2020. A convenience sampling technique was used, which resulted in a sample size of 937 participants. These participants included the entire roster of dental and medical students enrolled from the first year onward and the interns/house officers who gave consent for participation; students who did not provide consent were excluded from the study.

A questionnaire was developed, pretested, and validated twice during the research period. The study instrument was directed primarily toward senior medical and dental healthcare professionals who had research experience in providing their perspectives regarding the simplicity, relativity, and significance of the content of questionnaires. A pilot study was executed using a smaller sample of medical and dental students $(n=50)$. The records from the pilot study were not used in our final investigation.

The initial part of the survey focused on the demographic details of the participants; these included gender, age, geographical location, field, and year of study. The next part of the questionnaire was divided into five sections. The first had questions related to the smoking and medical status of the participants. The second section focused on queries related to oral hygiene, the frequency and duration of hand washing, the temperature of the water used for hand washing, the frequency of washing, and touching the face. The third had questions assessing the knowledge regarding the symptoms and transmission route of COVID-19. The fourth section related to different personal protection equipment that can be used and the related protocols. The last section focused on 
evaluating the general learning attitude of the participants toward the current pandemic.

\section{Statistical Analysis}

A convenience sampling technique was used for this study. Responses from online software were first exported to an Excel data sheet, then coded, and transformed to SPSS v26 IBM software for analytical purposes. Descriptive statistics (frequency, percentages, and mean standard deviation) were calculated. Comparisons of the knowledge score and attitude responses with demographic information were done using the independent $t$-test, one-way ANOVA, and Chi-square tests, as appropriate. The associations between the hygiene awareness with the knowledge status and attitude responses among the medical and dental students were described using Spearman's correlation; a $p$-value less than 0.05 was considered statistically significant.

\section{Results}

Of the 937 study participants, there were 353 (38\%) males and 582 (62\%) females; two students did not mark their gender. Among these, 680 (73\%) were dental students and 257 (27\%) were medical students, with an average of $20.79 \pm 2.1$ and $22.13 \pm 2.1$ years, respectively.

The demographic information regarding the participants in terms of percentages is presented in - Table 1. About $87 \%$ of the dental students claimed to be medically fit and well, while $4 \%$ reported heart disease and $9 \%$ suffered from arthritis. Although the majority of the medical students were also found to be medically fit and well, 9\% reported arthritis and $2 \%$ had heart problems.

The mean knowledge score among the female dental students $(5.15 \pm 1.08)$ was significantly higher than that of the male students ( $4.87 \pm 1.09$ ), while the knowledge score was not significant between the male and female dental students $(5.25 \pm 1.24$ and $5.18 \pm 1.08$, respectively). It is clear from - Table 2 that as the education level goes higher, the mean scores increase significantly; a similar pattern is noted for the dental and the medical students. The knowledge score was not significantly different among the places of residence (various locations) for the dental and medical students ( $p=0.833, p=0.55$, respectively). The highest mean score was found in the medical students from Azad Jammu and Kashmir (5.54 \pm 1.19 ), whereas an above average score was recorded in Balochistan and Gilgit Baltistan's dental students (5.33 \pm 1.113). The overall mean knowledge score was statistically higher in medical students as compared with dental students (5.21 $\pm 1.15,5.05 \pm 1.09 ; p=0.054$, respectively). Overall, $74 \%$ of the medical students answered correctly to all of the knowledge questions related to COVID-19, while $71 \%$ of the dental students gave the correct answers; these responses are presented in -Fig. $\mathbf{1}$.

Both the male and the female dental students displayed a statistically significant association with the fact that COVID-19 is a life-threating disease. - Table $\mathbf{3}$ shows that most of the
Table 1 Demographic information of dental and medical participants

\begin{tabular}{|c|c|c|}
\hline & $\begin{array}{l}\text { Dental } \\
\text { students } \\
n(\%)\end{array}$ & $\begin{array}{l}\text { Medical } \\
\text { students } \\
n(\%)\end{array}$ \\
\hline \multicolumn{3}{|l|}{ Gender } \\
\hline Male & $244(36)$ & $109(43)$ \\
\hline Female & $436(64)$ & $146(57)$ \\
\hline \multicolumn{3}{|l|}{ Location } \\
\hline Khyber Pakhtunkhwa & $316(47)$ & $163(63)$ \\
\hline Punjab & $108(16)$ & $33(13)$ \\
\hline Sindh & $216(32)$ & $38(19)$ \\
\hline Baluchistan & $15(2)$ & $7(3)$ \\
\hline Azad Jammu and Kashmir & $20(3)$ & $13(5)$ \\
\hline Gilgit Baltistan & $3(0.4)$ & $3(1)$ \\
\hline \multicolumn{3}{|l|}{ Year of study level } \\
\hline First & $233(34)$ & $38(15)$ \\
\hline Second & $219(32)$ & $41(16)$ \\
\hline Third & $117(17)$ & $58(23)$ \\
\hline Fourth & $70(10)$ & $51(20)$ \\
\hline Fifth & $4(0.6)$ & $50(19)$ \\
\hline Interns/house officers & $37(5.4)$ & $19(7)$ \\
\hline \multicolumn{3}{|l|}{ Smoking status } \\
\hline Yes & $23(3)$ & $18(7)$ \\
\hline No & $620(91)$ & $221(86)$ \\
\hline Occasional smoker & $26(4)$ & $13(5)$ \\
\hline Past smoker & $11(2)$ & $5(2)$ \\
\hline \multicolumn{3}{|l|}{ Frequency of smoke } \\
\hline $1-5$ cigarette & $37(93)$ & $15(83)$ \\
\hline More than 10 cigarettes & $3(7)$ & $3(17)$ \\
\hline \multicolumn{3}{|l|}{ Other type } \\
\hline Naswar & $22(73)$ & $15(65)$ \\
\hline Hukah/shesha & $8(27)$ & $8(35)$ \\
\hline
\end{tabular}

female dental students (68\%) were tired of hearing about COVID-19 comparisons to the male students (38\%). Although the COVID-19 as life threatening and tired of hearing percentage was also high in the female medical students, it was not significantly associated. Obtaining more information regarding COVID-19 was found higher in junior dental students (first year $=34 \%$ and second year $=33 \%$, whereas the percentage was high among senior medical students (third year $=24 \%$, fourth and fifth year $=19 \%$ ). A similar pattern was observed among both the medical and the dental students being tired of hearing about COVID-19. Although the geographic location was significantly associated with attitude toward COVID-19 among the medical students, it was not statistically significant among the dental students. The major source of COVID-19 related information for both the medical and the dental participants was through social media at 371 (39\%), television/radio (29\%), print media (newspaper), and friends/family (25\%) were 
Table 2 Knowledge score comparison between dental and medical participants with demographic characteristics

\begin{tabular}{|c|c|c|c|c|c|}
\hline & & Dental students & $p$-Value & Medical students & $p$-Value \\
\hline \multirow[t]{2}{*}{ Gender } & Male & $4.87 \pm 1.09$ & \multirow[t]{2}{*}{$0.001^{\mathrm{a}}$} & $5.25 \pm 1.24$ & \multirow[t]{2}{*}{0.634} \\
\hline & Female & $5.15 \pm 1.08$ & & $5.18 \pm 1.08$ & \\
\hline \multirow[t]{6}{*}{ Education level } & First & $5.02 \pm 1.05$ & \multirow[t]{6}{*}{$0.003^{\mathrm{a}}$} & $4.92 \pm 1.282$ & \multirow[t]{6}{*}{$0.02^{\mathrm{a}}$} \\
\hline & Second & $4.9 \pm 1.173$ & & $5.05 \pm 1.048$ & \\
\hline & Third & $5.17 \pm 1.147$ & & $5.1 \pm 1.003$ & \\
\hline & Fourth & $5.06 \pm 0.915$ & & $5.2 \pm 1.149$ & \\
\hline & Fifth & $5.75 \pm 0.5$ & & $5.42 \pm 1.23$ & \\
\hline & Interns/house officers & $5.62 \pm 0.861$ & & $5.95 \pm 1.026$ & \\
\hline \multirow[t]{6}{*}{ Location } & Khyber Pakhtunkhwa & $5.03 \pm 1.073$ & \multirow[t]{6}{*}{0.833} & $5.23 \pm 1.092$ & \multirow[t]{6}{*}{0.55} \\
\hline & Punjab & $4.98 \pm 1.127$ & & $5.06 \pm 1.248$ & \\
\hline & Sindh & $5.09 \pm 1.125$ & & $5.26 \pm 1.288$ & \\
\hline & Baluchistan & $5.33 \pm 1.113$ & & $4.57 \pm 1.397$ & \\
\hline & Azad Jammu and Kashmir & $5.1 \pm 0.912$ & & $5.54 \pm 1.198$ & \\
\hline & Gilgit Baltistan & $5.33 \pm 1.155$ & & $5 \pm 0$ & \\
\hline \multirow[t]{2}{*}{ Overall COVID-19 Score } & Dental students & \multicolumn{2}{|l|}{$5.05 \pm 1.09$} & \multirow[t]{2}{*}{$0.045^{\mathrm{a}}$} & \\
\hline & Medical students & \multicolumn{2}{|l|}{$5.21 \pm 1.15$} & & \\
\hline
\end{tabular}

aStatistically significant.

Percentage of correct responses between Dental and Medical studetns

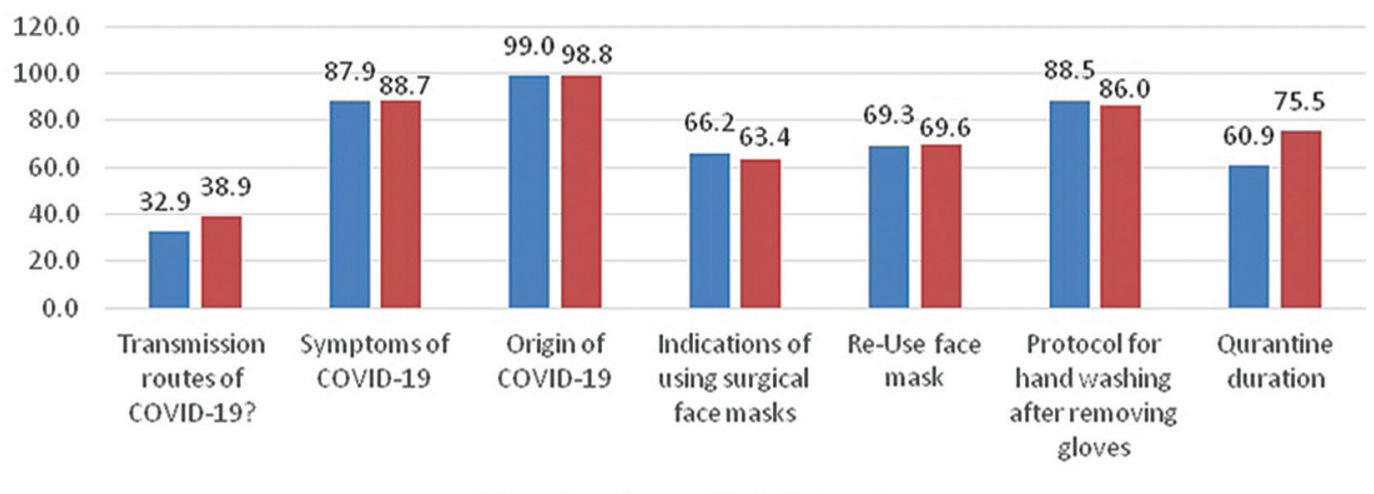

Fig. 1 Percentage of correct responses between dental and medical.

the next major sources providing relevant and preventative information regarding the virus.

The comparisons between the general hygiene awareness regarding COVID-19 among the dental and the medical students are shown in - Table 4 . The level of hygiene awareness between the two groups is almost the same. The only proportional difference noticed between the medical and the dental students was in the use of liquid soap: 125 (18\%) and $26(10 \%)$.

\section{Discussion}

COVID-19 is a global condition affecting millions of people worldwide. In considering the current trend of transmission of COVID-19, this study was undertaken to understand the level of awareness, knowledge, and attitude of undergraduate medical and dental students in Pakistan.

In this study, the majority of the participants were females and belonged to the Khyber Pakhtunkhwa (KPK) followed by the Sindh province. These findings are comparable to a study conducted by Khader et al, who stated that the females were generally more inclined toward admission in the medical and dental programs. ${ }^{20}$ They were also better at participating in the current research activity.

Smokers are considered to be at high risk of acquiring the COVID-19 infection, which can lead to compromised functioning capacity of the lungs and cause diseases such as emphysema, chronic obstructive pulmonary disease, chronic bronchitis, and lung cancer. ${ }^{21} \mathrm{~A}$ small number of the study 
Table 3 Association between demographic information and attitude toward COVID-19

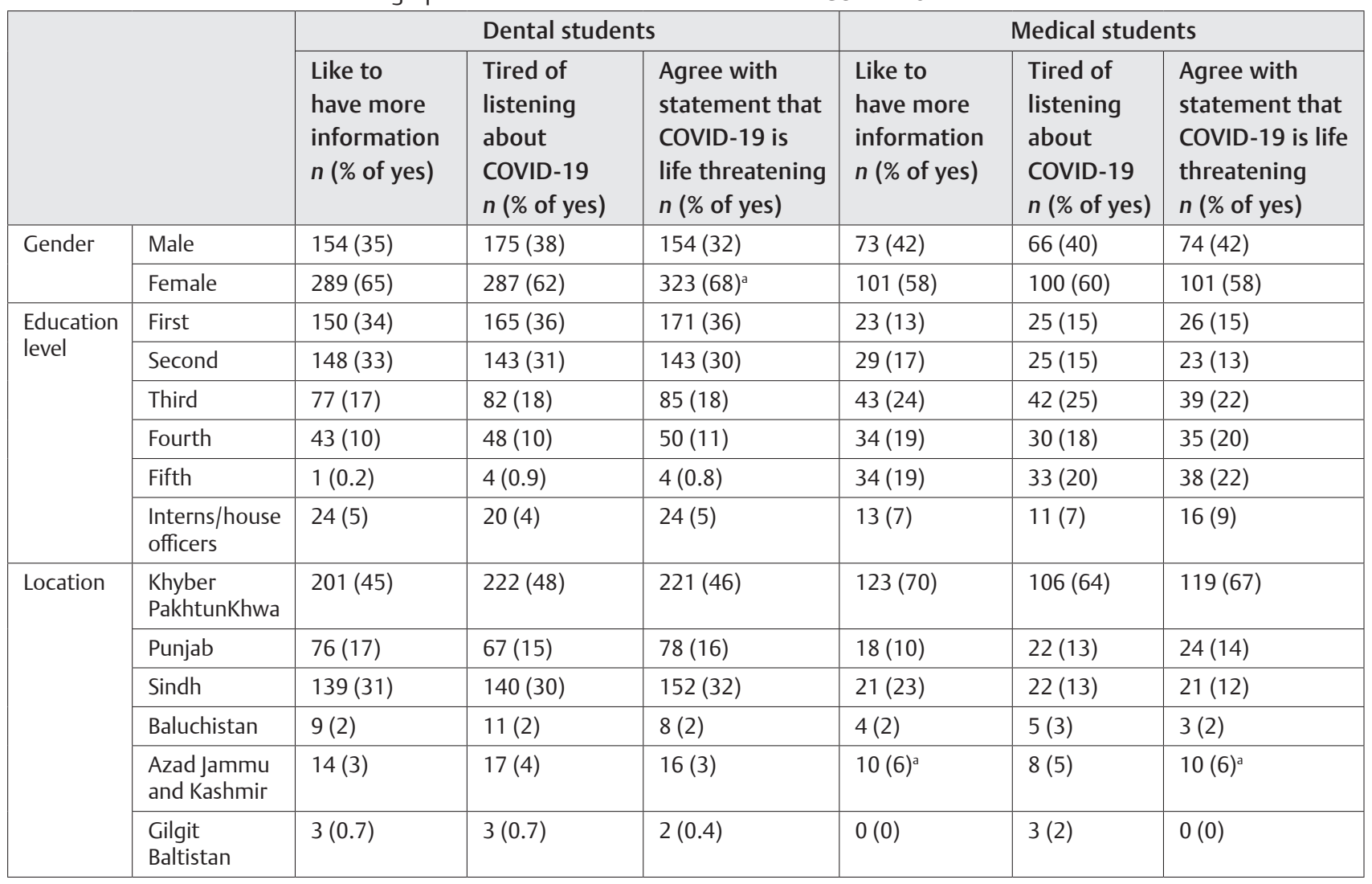

aStatistically significant.

Table 4 Comparison of hygiene awareness between dental and medical students

\begin{tabular}{|c|c|c|c|c|}
\hline \multicolumn{2}{|l|}{ Questions } & $\begin{array}{l}\text { Dental } \\
\text { students } n(\%)\end{array}$ & $\begin{array}{l}\text { Medical } \\
\text { students } n(\%)\end{array}$ & $p$-Values \\
\hline \multirow{4}{*}{$\begin{array}{l}\text { How many times do you } \\
\text { wash your hands? }\end{array}$} & Once a day & $10(2)$ & $3(1)$ & \multirow[t]{4}{*}{0.398} \\
\hline & Twice a day & $21(3)$ & $11(4)$ & \\
\hline & Multiple times a day & $614(90)$ & $226(88)$ & \\
\hline & Without soap (Wudu) & $35(5)$ & $17(6)$ & \\
\hline \multirow{5}{*}{$\begin{array}{l}\text { How many times do you } \\
\text { wash your face? }\end{array}$} & Once a day & $23(3)$ & $3(4)$ & \multirow[t]{5}{*}{0.886} \\
\hline & Twice a day & $78(12)$ & $11(11)$ & \\
\hline & Multiple times a day & $245(36)$ & $226(39)$ & \\
\hline & Five times Wudu (Wuzu) & $321(47)$ & $1(44)$ & \\
\hline & Not regularly (occasionally) & $12(2)$ & $16(2)$ & \\
\hline \multirow{5}{*}{$\begin{array}{l}\text { What is the duration of hand } \\
\text { washing? }\end{array}$} & $10 \mathrm{~s}$ & $217(32)$ & $85(33)$ & \multirow[t]{5}{*}{0.534} \\
\hline & $10-20 \mathrm{~s}$ & $364(54)$ & $134(52)$ & \\
\hline & More than $20 \mathrm{~s}$ & $78(12)$ & $32(13)$ & \\
\hline & $1 \mathrm{~min}$ & $17(2)$ & $0(0)$ & \\
\hline & $2 \min$ & $3(0.4)$ & $5(2)$ & \\
\hline \multirow{4}{*}{$\begin{array}{l}\text { What kind of soap do } \\
\text { you use? }\end{array}$} & Plain soap & $196(29)$ & $103(40)$ & \multirow[t]{4}{*}{$0.001^{\mathrm{a}}$} \\
\hline & Antibacterial soap & $355(52)$ & $126(49)$ & \\
\hline & Cloth washing soap & $2(0.3)$ & $1(0.4)$ & \\
\hline & Liquid soap & $125(18)$ & $26(10)$ & \\
\hline \multirow{3}{*}{$\begin{array}{l}\text { Are you aware of hand } \\
\text { washing technique? }\end{array}$} & Yes & $624(92)$ & $240(93)$ & \multirow[t]{3}{*}{0.407} \\
\hline & No & $21(3)$ & $12(5)$ & \\
\hline & Not sure & $34(5)$ & $4(2)$ & \\
\hline
\end{tabular}

aStatistically significant. 
participants answered smoking more than 10 cigarettes per day, that is, dental (7\%), medical (17\%) as compared with one to five cigarettes per day dental (93\%), medical (83\%) students, respectively. This is a positive finding since the study conducted by Liu et al identified severe consequences for COVID-19 positive patients having a history of smoking. ${ }^{22}$ Moreover, with lockdown, family members can be exposed to the passive smoking; therefore, smoking cessation is the utmost strategy that should be followed.

Various routes of transmission of COVID-19 infection have been identified, including human-to-human contact, aerosol, and through an endogenous route. ${ }^{23}$ In our study, medical students had a better understanding regarding the mode of transmission, as compared with the dental students. These results are consistent with a study lead by Khan et al, who found that healthcare workers have better knowledge. ${ }^{24}$ This can be additionally attributed to the fact that medical students study different diseases in detail and thus have greater knowledge. Therefore, more attention needs be directed toward the dental students to enhance their education level in this regard.

Fever, headache, and sore throat are a few of the most frequently identified indicators of COVID-19. Medical students had more knowledge regarding the symptoms than the dental students. These results are comparable to a survey conducted by Bhagavathula et al, who highlighted that doctors have better understanding. ${ }^{25}$ However, these results differ from those of a study conducted by Khader et al, who noted that dentists had adequate information in relation to the symptoms that play a crucial role in preventing the spread of the disease. ${ }^{20}$

Dental students routinely use face masks while treating patients for various dental problems. In our study, when compared with the medical students, the dental students had better understanding regarding the usage of surgical face masks. Comparable results were noted by Vinita et al, who noted that dentists have better understanding regarding the correct usage of surgical face masks, as dentists are more familiar with their role in protecting against infections. ${ }^{26}$ The dental students also had a better understanding in following the correct protocol for handwashing, as they have higher patient contact and a lot of emphasis is placed on hand washing after every patient. These results contradict the study led by Basurrah and Madani, who noted better adherence to hand hygiene by healthcare workers. ${ }^{27}$

Both medical and dental students had sufficient familiarity about the origin of COVID-19. These results are consistent with a study led by Mubeen et al in which participants correctly identified China as the origin of the current pandemic. ${ }^{28}$

Adequate knowledge regarding the usage of a face mask in providing protection against COVID-19 was seen among the participants. These results are consistent with a study conducted in China, where the majority of the participants preferred using a mask to protect themselves. ${ }^{29}$ Another survey conducted by Baloran, in Philippines, reported that 90\% of the studied population understood the importance of face masks in providing protection against this viral infection. ${ }^{30}$
In this current study, statistically significant results were noted with respect to the hand washing principles among the medical and dental students. Hand hygiene plays a crucial role in providing safety against different infections. The study results revealed a positive approach of students in following proper hand washing techniques, washing the hands for the required duration of time, and using antibacterial soap for washing. These results are in agreement with a study conducted by Alzoubi et al, who also highlighted hand washing as an important method involved in providing protection against COVID-19. ${ }^{31}$

Social media platforms provide significant information; among them, with approximately 40 million users in 2019, Facebook is the main social means utilized by users all over the world. ${ }^{32}$ It is noteworthy that approximately $40 \%$ of our participants preferred gathering facts regarding the pandemic from social media, followed by radio and television. These results are in agreement with a study conducted by Huynh et al in China, where approximately $91 \%$ of the participants gathered information through social media, followed by television. These results show that people currently prefer social media as opposed to official government websites for getting facts. ${ }^{33}$

The majority of the female dental participants recognized COVID-19 as a life-threatening condition. These results are consistent with surveys conducted by Abdelhafiz et al and Li et al, who also considered COVID19 as a serious infection; $3^{4,35}$ hence, requiring that proper infection control protocols be followed. After collecting data from all of the provinces of Pakistan, the highest response rate was received from the KPK province, where many dental students were tired of hearing news regarding the coronavirus.

The main strength of the current study is in its large sample size, which was enrolled during a precarious time of the initial stage of the outbreak of the COVID-19 pandemic. However, it has higher representation by females and dental students.

\section{Limitations}

The limitations of this study include that questionnaire studies without interviews give an over or under estimation of the responses, so the results may not be generalized. Additionally, only those students who had access to the internet, were in contact with their peers and teachers, and had social app accounts would have been aware of the study, which is a selection bias. Furthermore, the response rate was low from the male gender, medical students (as compared with their large number strength), in comparison to the dental students. The sample size was also lower in number than expected in some provinces.

\section{Recommendations}

Concerted efforts are required through institutional, educational, and health promotion campaigns using current social media platforms and webinars by experts in public health, infection control, and healthcare policy makers targeting the 
medical and dental students to substantiate their knowledge to reflect in their practices in the near future with confidence and professional integrity.

Future studies may consider a larger representative sample size, pre- and post-health care awareness campaigns, and feedback assessments. Better participation and higher numbers are needed for the medical and dental student participants. Future studies may focus on a representative student sample from throughout the country.

\section{Conclusion}

Pakistani medical and dental students were aware of the importance of use of face masks in preventing COVID-19. Medical students were also aware of the mode of transmission and the symptoms of COVID-19; they had sufficient knowledge of its origin. In comparison, dental students showed better understanding of the use of surgical masks and the correct protocol for hand washing. Social media proved to be the main source of information regarding the pandemic for the students. The majority of the participants were females and from the KPK province.

\section{Funding}

None.

\section{Conflict of Interest}

None declared.

\section{Acknowledgments}

The authors are thankful to all the students who participated in this study. They are also grateful to all the faculty members who helped in the dissemination of the online questionnaire link in their respective institutes.

\section{References}

1 Dryhurst S, Schneider CR, Kerr J, et al. Risk perceptions of COVID-19 around the world. J Risk Res 2020;5:1-3

2 Cascella M, Rajnik M, Cuomo A, et al. Features, evaluation and treatment coronavirus (COVID-19). In: Statpearls 2020. Treasure Island, FL: StatPearls Publishing, 2020

3 Su S, Wong G, Shi W, et al. Epidemiology, genetic recombination, and pathogenesis of coronaviruses. Trends Microbiol 2016;24(6):490-502

4 Fallahi HR, Keyhan SO, Zandian D, Kim SG, Cheshmi B. Being a front-line dentist during the Covid-19 pandemic: a literature review. Maxillofac Plast Reconstr Surg 2020;42(1):12 doi:10.1186/s40902-020-00256-5

5 Ali S, Noreen S, Farooq I. COVID-19 and health care workers in Pakistan. Are we losing the fight? J Med Sci 2020;28(2):186-188

6 Yang Y, Peng F, Wang R, et al. The deadly coronaviruses: the 2003 SARS pandemic and the 2020 novel coronavirus epidemic in China. J Autoimmun 2020;109:102434

7 Di Gennaro F, Pizzol D, Marotta C, et al. Coronavirus diseases (COVID-19) current status and future perspectives: a narrative review. Int J Environ Res Public Health 2020;17(8):2690

8 World Health Organization Covid 19 Infection. Available at: https://www.who.int/emergencies/diseases/novel-coronavirus-2019. Accessed March 31, 2020
9 Sohrabi C, Alsafi Z, O'Neill N, et al. World Health Organization declares global emergency: a review of the 2019 novel coronavirus (COVID-19). Int J Surg 2020;76:71-76

10 World Health Organization. 2020. Novel coronavirus (COVID-19) situation URL: Available at: https://covid19.who. int/. Accessed March 12, 2020

11 Saqlain M, Munir MM, Rehman SU, et al. Knowledge, attitude, practice and perceived barriers among healthcare workers regarding COVID-19: a cross-sectional survey from Pakistan. J Hosp Infect 2020;105(3):419-423

12 Worldometer, 2020 Available at: https://www.worldometers. info/coronavirus/country/pakistan. Accessed June 17, 2020

13 World Health Organization. WHO Director-General's opening remarks at the media briefing on COVID-19-11 March 2020. Geneva, Switzerland. Available at: https://www. who.int/dg/speeches/detail/who-director-general-s-opening-remarks-at-the-media-briefing-on-covid-19-11march-2020. March 2020

14 Qian X, Ren R, Wang Y, et al; Members of Steering Committee, Society of Global Health, Chinese Preventive Medicine Association. Fighting against the common enemy of COVID-19: a practice of building a community with a shared future for mankind. Infect Dis Poverty 2020;9(1):34

15 Saqlain M, Munir MM, Ahmed A, Tahir AH, Kamran S. Is Pakistan prepared to tackle the coronavirus epidemic? Drugs Ther Perspect 2020;20:1-2

16 Ali S, Farooq I, Abdelsalam M, AlHumaid J. Current clinical dental practice guidelines and the financial impact of COVID-19 on dental care providers. Eur J Dent 2020;14(suppl S1): S140-S145 doi:10.1055/s-0040-1716307

17 Ali S, Noreen S, Farooq I, Bugshan A, Vohra F. Risk assessment of health care workers at the frontline against COVID-19. Pak J Med Sci 2020;36(4):99-103

18 Ikhlaq A, Bint-E-Riaz H, Bashir I, Ijaz F. Awareness and attitude of undergraduate medical students towards 2019-novel corona virus. Pak J Med Sci 2020;36(COVID19-S4) :S32-S36

19 Ahmed N, Khan A, Naveed HA, Moizuddin SM, Khan J. Concerns of undergraduate medical students towards an outbreak of COVID-19. Int J Curr Med Phar Res 2020;6(3):5055-5062

20 Khader Y, Al Nsour M, Al-Batayneh OB, et al. Dentists' awareness, perception, and attitude regarding COVID-19 and infection control: cross-sectional study among Jordanian dentists. JMIR Public Health Surveill 2020;6(2):e18798

21 Ahmed N, Maqsood A, Abduljabbar T, Vohra F. tobacco smoking a potential risk factor in transmission of COVID-19 infection. Pak J Med Sci 2020;36(COVID19-S4) :S104-S107

22 Liu W, Tao ZW, Wang L, et al. Analysis of factors associated with disease outcomes in hospitalized patients with 2019 novel coronavirus disease. Chin Med J (Engl) 2020;133(9):1032-1038

23 Farooq I, Ali S, Moheet IA, AlHumaid J. COVID-19 outbreak, disruption of dental education, and the role of teledentistry. Pak J Med Sci 2020;36(7):1726-1731

24 Khan MU, Shah S, Ahmad A, Fatokun O. Knowledge and attitude of healthcare workers about Middle East Respiratory Syndrome in multispecialty hospitals of Qassim, Saudi Arabia. BMC Public Health 2014;14:1281

25 Bhagavathula AS, Aldhaleei WA, Rahmani J, Mahabadi MA, Bandari DK. Knowledge and perceptions of COVID-19 among health care workers: cross-sectional study. JMIR Public Health Surveill 2020;6(2):e19160

26 Mary V, Kesavan R, Lakshmi T, et al. J Indian Dent Assoc Madras 2019;6(4):117-124

27 Basurrah MM, Madani TA. Handwashing and gloving practice among health care workers in medical and surgical wards in a tertiary care centre in Riyadh, Saudi Arabia. Scand J Infect Dis 2006;38(8):620-624 
28 Mubeen SM, Kamal S, Kamal S, Balkhi F. Knowledge and awareness regarding spread and prevention of COVID-19 among the young adults of Karachi. J Pak Med Assoc 2020;70(5):S169-S174

29 Zhong BL, Luo W, Li HM, et al. Knowledge, attitudes, and practices towards COVID-19 among Chinese residents during the rapid rise period of the COVID-19 outbreak: a quick online cross-sectional survey. Int J Biol Sci 2020;16(10):1745-1752

30 Baloran ET. Knowledge, Attitudes, Anxiety, and Coping Strategies of Students during COVID-19 Pandemic. J Loss Trauma 2020;1-8

31 Alzoubi $\mathrm{H}$, Alnawaiseh N, Al-Mnayyis A, et al. COVID-19-knowledge, attitude and practice among medical and non-medical University Students in Jordan. J Pure Appl Microbiol 2020;14:17-24
32 Abdelhafiz AS, Fouda MA, El-Jaafary SI, et al. Targeting future customers: an introductory biobanking course for undergraduate students of life sciences. Biopreserv Biobank 2017; 15(4):350-359

33 Huynh G, Nguyen TN, Vo KN, Pham LA. Knowledge and attitude toward COVID-19 among healthcare workers at District 2 Hospital, Ho Chi Minh City. Asian Pac J Trop Med 2020;13(6):260

34 Abdelhafiz AS, Mohammed Z, Ibrahim ME, et al. Knowledge, perceptions, and attitude of egyptians towards the novel coronavirus disease (COVID-19). J Community Health 2020;45(5):881-890

35 Li LQ Huang T, Wang YQ et al. COVID-19 patients' clinical characteristics, discharge rate, and fatality rate of meta-analysis. J Med Virol 2020;92(6):577-583 